\title{
Direct and negative regulation of the sycO-ypkA-ypoJ operon by cyclic AMP receptor protein (CRP) in Yersinia pestis Lingjun Zhan ${ }^{\dagger 1,2}$, Lei Yang ${ }^{\dagger 1,2}$, Lei Zhou ${ }^{\dagger 1}$, Yingli Li ${ }^{1}$, He Gao ${ }^{1}$, Zhaobiao Guo1, Lianfeng Zhang ${ }^{2}$, Chuan Qin ${ }^{2}$, Dongsheng Zhou*1 and Ruifu Yang*1
}

\author{
Address: ${ }^{1}$ State Key Laboratory of Pathogen and Biosecurity, Beijing Institute of Microbiology and Epidemiology, Beijing 100071, PR China and \\ 2Institute of Laboratory Animal Sciences, Chinese Academy of Medical Peking Union Medical College, Beijing, 100021, PR China \\ Email: Lingjun Zhan - zhanlingjun773@sina.com.cn; Lei Yang - yanglei200609@126.com; Lei Zhou - ammszhoulei@gmail.com; \\ Yingli Li - liyingli301@163.com; He Gao - gaohe@yahoo.cn; Zhaobiao Guo - wzj_lyl@tom.com; Lianfeng Zhang - lianfeng- \\ zhang3@yahoo.com.cn; Chuan Qin - qinchuan@pumc.edu.cn; Dongsheng Zhou* - dongshengzhou1977@gmail.com; \\ Ruifu Yang* - ruifuyang@gmail.com \\ * Corresponding authors †Equal contributors
}

Published: 25 August 2009

BMC Microbiology 2009, 9:178 doi:10.1186/147I-2180-9-178
Received: 2I November 2008

Accepted: 25 August 2009

This article is available from: http://www.biomedcentral.com//47I-2/80/9/I78

(c) 2009 Zhan et al; licensee BioMed Central Ltd.

This is an Open Access article distributed under the terms of the Creative Commons Attribution License (http://creativecommons.org/licenses/by/2.0), which permits unrestricted use, distribution, and reproduction in any medium, provided the original work is properly cited.

\begin{abstract}
Background: Pathogenic yersiniae, including Y. pestis, share a type III secretion system (T3SS) that is composed of a secretion machinery, a set of translocation proteins, a control system, and six Yop effector proteins including YpkA and YopJ. The cyclic AMP receptor protein (CRP), a global regulator, was recently found to regulate the laterally acquired genes (pla and pst) in $Y$. pestis. The regulation of T3SS components by CRP is unknown.
\end{abstract}

Results: The sycO, ypkA and yopJ genes constitute a single operon in $Y$. pestis. CRP specifically binds to the promoter-proximate region of sycO, and represses the expression of the sycO-ypkA-yopJ operon. A single CRP-dependent promoter is employed for the sycO-ypkA-yopJ operon, but two CRP binding sites (site I and site 2) are detected within the promoter region. A CRP box homologue is found in site I other than site 2. The determination of CRP-binding sites, transcription start site and core promoter element (-10 and -35 regions) promotes us to depict the structural organization of CRP-dependent promoter, giving a map of CRP-promoter DNA interaction for sycO-ypkA-yopJ.

Conclusion: The sycO-ypkA-yopJ operon is under the direct and negative regulation of CRP in $Y$. pestis. The sycO-ypkA-yopJ promoter-proximate regions are extremely conserved in $Y$. pestis, $Y$. pseudotuberculosis and $Y$. enterocolitica. Therefore, data presented here can be generally applied to the above three pathogenic yersiniae. 


\section{Background}

Plague, caused by Yesinia pestis, is a zoonotic disease that threatened public health seriously. The three pathogenic Yersinia species, Y. pestis, Y. pseudotuberculosis, and Y. enterocolitica, share a type III secretion system (T3SS) that is composed of a secretion machinery, a set of translocation proteins, a control system, and six Yop effector proteins $[1,2]$. Through the T3SS, pathogenic yersiniae inject effectors into the cytosol of eukaryotic cells when docking at the surface of host cell. The injected Yops perturb the signaling cascades that activate the processes of phagocytosis, cytokine release and respiratory burst. As a result, phagocytosis is inhibited, recruitment of PMNs and monocyte-derived macrophages is reduced, and lymphocyte proliferation is prevented.

The cyclic AMP receptor protein (CRP) is a global regulator that controls the transcription initiation for more than 100 bacterial genes/operons [3]. CRP is activated by cyclic AMP (cAMP), forming the CAMP-CRP complex. This complex binds a symmetrical consensus DNA sequence TGTGA-N ${ }_{6}$-TCACA (known as the CRP box sequence) located within the upstream promoter regions. The CRPpromoter DNA interaction is crucial for the regulation of target genes.

CRP and its homologues are required for virulence and/or expression of virulence genes in several pathogens, including Y. pestis [4], Y. enterocolitica [5], Vibrio vulnificus [6], Vibrio cholerae [7] and Mycobacterium tuberculosis [8]. The crp disruption in $Y$. pestis attenuates both in vitro and in vivo growth of the mutant, and leads to a $>15,000$-fold loss of virulence after subcutaneous infection, but a less than 40-fold increase in LD50 by intravenous inoculation [4]. CRP plays a role in the globally transcriptional regulation of genes including a wide set of virulence genes in $Y$. pestis [4]. Especially, it directly stimulates the expression of plasminogen activator (Pla) [4,9], a virulence factor essential for bubonic and primary pneumonic plague $[10,11]$.

Yersinia protein kinase A (YpkA) and Yersinia outer protein $\mathrm{J}$ (YopJ) are encoded by plasmid pCD1-borne $y p k A$ and yopJ genes in Y. pestis, respectively. YpkA/YopO is a serine/threonine protein kinase involved in host actin cytoskeletal rearrangements and in inhibition of phagocytosis [12], while YopJ/YopP acts as an acetyltransferase inhibiting mitogen-activated protein kinase (MAPK) and the nuclear factor kappaB (NFkB) signaling pathways used in innate immune response [13]. Both of them are the effector proteins of T3SS and essentially contribute to the virulence of $Y$. pestis $[2,14]$. SycO is a T3SS chaperone that increases solubility and secretion efficiency of the effector YpkA/YopO [15].
In the present work, we disclosed that CRP directly and negatively regulated the $s y c O-y p k A-y o p J$ operon in $Y$. pestis under the calcium-rich condition, by using real-time RTPCR, LacZ reporter fusion, electrophoretic mobility shift assay (EMSA), and DNase I footprinting assay. Data presented here further validated the important role of CRP in virulence of $Y$. pestis.

\section{Methods \\ Bacterial strains}

The wild-type (WT) Y. pestis strain 201 belongs to a newly established $Y$. pestis biovar, Microtus [16], which was thought to be avirulent to humans, but highly virulent to mice. An in-frame deletion of the crp gene was constructed by using one step inactivation method [17], generating a mutant strain referred to as $\operatorname{crp}$ [4]. Bacteria were grown in Luria-Bertani (LB) broth or chemically defined $\mathrm{TMH}$ medium [18] at 26 or $37^{\circ} \mathrm{C}$. E. coli was grown in LB broth at $37^{\circ} \mathrm{C}$. When needed, antibiotics were added at the following concentrations: $100 \mu \mathrm{g} / \mathrm{ml}$ for ampicillin, $50 \mu \mathrm{g} /$ $\mathrm{ml}$ for kanamycin, and $34 \mu \mathrm{g} / \mathrm{ml}$ chloramphenicol.

\section{Bacterial growth and RNA isolation}

The WT and $\operatorname{crp}$ were grown at $26^{\circ} \mathrm{C}$ in the TMH medium with the addition of $1 \mathrm{mM}$ cAMP (referred to as 'TMH$1 \mathrm{mM}$ cAMP') to an $\mathrm{OD}_{620}$ of about 1.0, and then diluted by 20 -fold into the fresh 'TMH- $1 \mathrm{mM}$ cAMP' medium for cultivating at $26^{\circ} \mathrm{C}$ until an $\mathrm{OD}_{620}$ of about 1.0 , and finally transferred to $37^{\circ} \mathrm{C}$ for $3 \mathrm{~h}$. Bacterial cells were harvested for the isolation of total RNA. Immediately before harvesting, bacterial cultures were mixed with RNAprotect Bacteria Reagent (Qiagen) to minimize RNA degradation. Total RNA was isolated using the MasterPure ${ }^{\mathrm{TM}}$ RNA Purification kit (Epicenter). Contaminated DNA in RNA samples was removed by using the Amibion's DNA-free ${ }^{\mathrm{TM}} \mathrm{Kit}$. RNA quality was monitored by agarose gel electrophoresis and RNA quantity was measured by spectrophotometer.

\section{Real-time RT-PCR}

Gene-specific primers (Table 1) were designed to produce a 150 to $200 \mathrm{bp}$ amplicon for each gene. cDNAs were generated by using $5 \mu \mathrm{g}$ of RNA and $3 \mu \mathrm{g}$ of random hexamer primers. Using three independent cultures and RNA preparations, real-time PCR was performed in triplicate as described previously [4], through the LightCycler system (Roche) together with the SYBR Green master mix. Based on the standard curve of 16S rRNA expression for each RNA preparation, the relative mRNA level was determined by the classic $\Delta \mathrm{Ct}$ method. $16 \mathrm{~S}$ rRNA gene was used to normalize that of all the other genes. The transcriptional variation between the WT and crp strains was then calculated for each gene. A mean ratio of two was taken as the cutoff of statistical significance. 
Table I: Oligonucleotide primers used in this study

\begin{tabular}{|c|c|}
\hline Target gene & Primer sequence $\left(5^{\prime} \rightarrow 3^{\prime}\right)$ \\
\hline \multicolumn{2}{|c|}{ EMSA (Sense/antisense) } \\
\hline sycO & ATATTCTGGGACGGGTTT/TTCCTGCTGAGTTTCTGC \\
\hline YPOI099 & AGCCCTCTCTCCCTAGCC/GCAGTTGCCAGACCGC \\
\hline YPO0I80 & GCTACCGAGCCTAACCC/AGGCACCCATCTCATGG \\
\hline \multicolumn{2}{|c|}{ Real-time PCR or RT-PCR (Sense/antisense) } \\
\hline sycO & GCCCTTGTTTCGCTTGGAGTG/AGTTCCTGCTGAGTTTCTGCTG \\
\hline ypkA & GCTAAGATTGAACGCTCCATTG/TCAGAACAACGCCAACCATC \\
\hline yopJ & AATCCAGGCGAACAATAAATATCC/CACTGAAATGTATTCCACCTTCC \\
\hline sycO-ypkA intergenic & CAGGAACTGCCCCTTCATAC/ATACCGTTTTCCTCCGATATTGAG \\
\hline ypkA-yopJ intergenic & TGCGAGAGCTGACGACCATC/TCATTACTGATTAAAGAACTGGTC \\
\hline lacA & CCGATAACGATTGGCAATAACG/GCGAATAACCCGACAAGGAAC \\
\hline I6s rRNA & TTACCTACTCTTGACATCCAC/GCTGGCAACAAAGGATAAG \\
\hline \multicolumn{2}{|c|}{ DNase I footprinting (Sense/antisense) } \\
\hline sycO & CAGATTTGTCTACAGGTTCG/CTCAGCATAATAACGACTCGG \\
\hline \multicolumn{2}{|c|}{ LacZ reporter fusion (Sense/antisense) } \\
\hline sycO & GCGGAATTCAGGAACGGGAAGATTTAC/GCGGGATCCAATCTCTCTGCATGAACG \\
\hline \multicolumn{2}{|l|}{ Primer extension } \\
\hline sycO & CTCAGCATAATAACGACTCGG \\
\hline
\end{tabular}

LacZ reporter fusion and -Galactosidase assay

A 408 bp promoter-proximate of $c y c O$ (Table 1) was cloned directionally into the EcoRI and BamHI sites of plasmid pRS551 expressing LacZ, which was verified by DNA sequencing. The recombinant plasmids were introduced into the WT and crp, respectively. The plasmid pRS551 was also transformed as negative control. The resulting strains were grown as described in RNA isolation. $\beta$-Galactosidase activity was determined for each strain by using the Promega $\beta$-Galactosidase Enzyme Assay System [4]. Assays were performed in triplicate.

\section{DNA-binding assays}

Preparation of purified recombinant His-CRP protein, electrophoretic mobility shift assay (EMSA) and DNase I footprinting assay were conducted as described previously [4]. For EMSA, a 468 bp promoter-proximate region of $c y c O$ (containing a predicted CRP binding site) or the corresponding cold probe (i.e. unlabeled target DNA) (Table 1) was radioactively labeled, incubated with increasing amounts of purified His-CRP protein, and then subjected to $4 \%(\mathrm{w} / \mathrm{v})$ polyacrylamide gel electrophoresis. In the DNase I footprinting experiments, coding or noncoding strand (261 bp in length) containing the predicted CRP binding site was labeled with $\left[\gamma^{-32} \mathrm{P}\right]$ at the 5 ' end, then, incubated with increasing amounts of His-CRP; after partial digestion with DNase I, the resulting fragments were analyzed by denaturing gel electrophoresis. Radioactive species were detected by autoradiography.

\section{Primer extension analysis}

For the primer extension assay [4], an oligonucleotide primer (Table 1) complementary to a portion of the RNA transcript of each gene was employed to synthesize cDNAs from the RNA templates. Electrophoresis of primer extension products was performed with a $6 \%$ polyacrylamide/8M urea gel. The yield of each primer extension product would indicate the mRNA expression level of the corresponding gene in each strain, and further could be employed to map the 5 ' terminus of RNA transcript for each gene.

\section{Results}

The sycO, ypkA and yopJ genes constitute a single operon The RT-PCR assay indicated that the sycO, ypkA and yopJ genes (designated as pCD12, pCD13 and pCD14 in Y. pestis 91001 [19], respectively) were transcribed as a single primary RNA (Fig. 1), and thereby these three genes constituted a single operon in Y. pestis Microtus strain 201.

\section{CRP greatly represses transcription of the sycO-ypkA- yopJ operon}

Our previous CDNA microarray analysis showed that the transcription of $s y c \mathrm{O}, y p k A$ and $y o p J$ was repressed by CRP [4]. Herein, the real-time RT-PCR assays confirmed that these three genes were up-regulated by more than 50 folds in the crp mutant in relative to the WT strain (Fig. 2). Taken together, transcription of the sycO-ypkA-yopJ operon was under the negative control of CRP. 


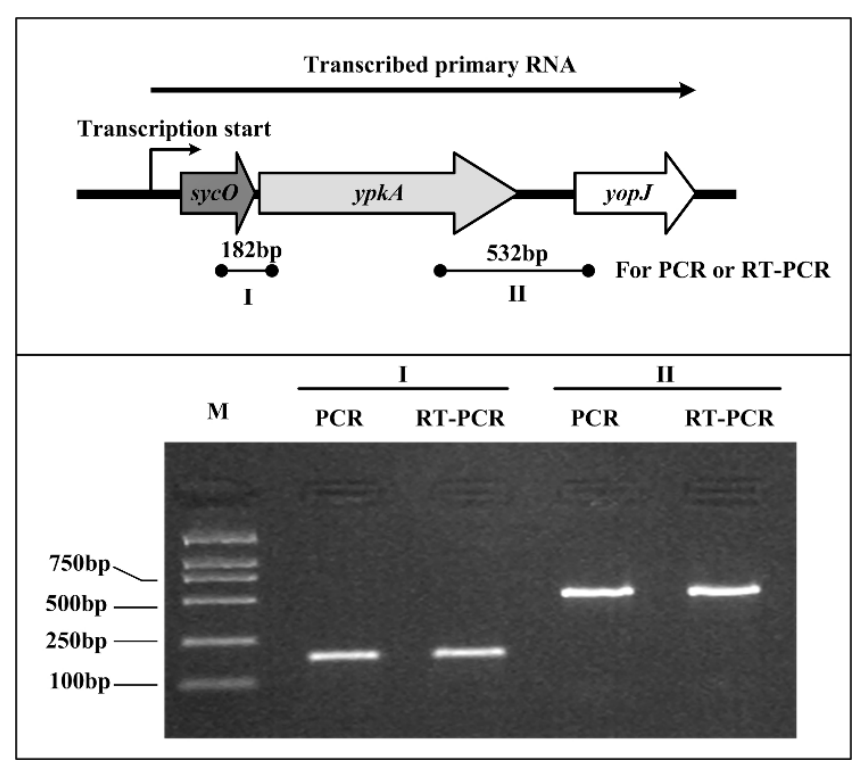

Figure I

Transcriptional organization of the sycO-ypkA-yopJ operon. Arrows represent the length and direction of transcription of sycO, ypkA and yopJ on PCDI. The horizontal arrow depicts the putative primary RNA transcript. The arrowheads indicate the location of primer pair and the expected amplicons. Genomic DNA and cDNA generated by RT were used as the templates for PCR and RT-PCR, respectively. To ensure that there was no contamination of genomic DNA in the RT reactions, negative controls of RTPCR were performed using 'cDNA' generated without reverse transcriptase as templates. Reactions containing primer pairs without template were also included as blank controls. As expected, both negative and blank controls of RT-PCR gave no amplicon (data not shown).

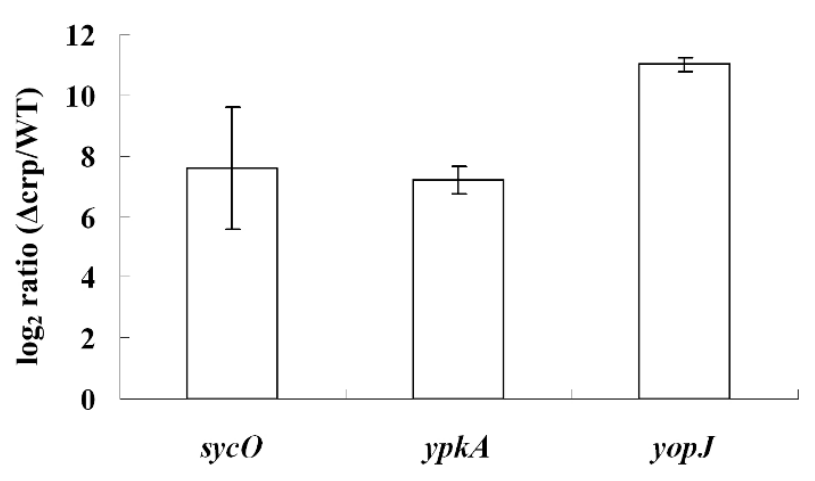

Figure 2

CRP-dependent transcription of sycO, ypkA and yopJ. Shown was the mean $\log _{2}$ ratio ( crp versus WT) of mRNA level for each gene.

\section{CRP greatly represses promoter activity of sycO-ypkA-} yopJ

To test the action of CRP on the sycO-ypkA-yopJ promoter activity, we constructed the sycO::lacZ fusion promoter consisting of a $690 \mathrm{bp}$ promoter-proximate region of $s y \mathrm{CO}$ and promoterless $l a c Z$, and then transformed into the WT and $c r p$, respectively. Empty vector pRS551 was also introduced into them, respectively, as controls. -galactosidase activity was measured for evaluating the sycO-ypkA-yopJ promoter activity in each strain. Since the crp mutation had an effect on the copy number of recombinant or empty pRS551 plasmid [4], a normalized fold change in the activity of each fusion promoter in $\mathrm{WT}$ in relative to crp was calculated to avoid the influence of copy number of pRS551 (Table 2).

Accordingly, the -galactosidase activity in the crp increased compared to the WT when they grew in the 'TMH-1mM CAMP' medium, indicating that CRP greatly repressed the promoter activity of sycO-ypkA-yopJ (Table 2).

\section{CRP binds to promoter-proximate region of sycO-ypkA- yopJ}

A CRP box-like sequence was found in the promoter-proximate region of sycO-ypkA-yopJ [4], indicating the direct association of CRP with the sycO-ypkA-yopJ promoter region. Further EMSA experiments showed that the CAMPCRP complex bound to the sycO-ypkA-yopJ promoter region in a CRP dose-dependent manner (Fig. 3a). CRP could not bind to the target DNA in the absence of cAMP.

To validate the specificity of CRP-DNA interaction, YPO0180 and YPO1099 [gene IDs in CO92 [20]] were used as negative controls (Fig. 3b). The PCR-generated upstream DNA of YPO0180 did not harbor the predicted CRP binding site, while the YPO1099 upstream region gave an extremely low score value of 0.96 during the pattern matching analysis using the CRP consensus ( $\mathrm{sycO}$ gave a score value of 8.57) [4]. Both of them gave negative EMSA result, even the CRP protein was increased to $4 \mu \mathrm{g}$ in a single reaction mixture (Fig. $3 \mathrm{~b}$ ).

Therefore, CRP specifically bound to the sycO-ypkA-yopJ promoter region and directly repressed the transcription of sycO-ypkA-yopJ.

\section{Structural organization of CRP-dependent sycO-ypkA- yopJ promoter}

In order to locate the precise CRP binding site within the sycO-ypkA-yopJ promoter region, DNase I footprinting assay was performed with both coding and non-coding strands. As shown in Fig. 4, CRP protected two distinct 
Table 2: Promoter activity determined with the sycO:IacZ reporter fusion

\begin{tabular}{lccc}
\hline & \multicolumn{2}{c}{ Fold change $($ crp/WT $)$} & Normalized fold change of promoter activity in crp in relative to WT \\
\cline { 2 - 3 } LacZ fusion & Plasmid copy number & Miller units & \\
\hline PsycO-lacZ & 0.006 & 0.182 & 30.33 \\
\hline
\end{tabular}

-Galactosidase activity (miller units) was detected as the promoter activity. An extremely low promoter activity was detected for the crp or WT transformed with empty PRS55I (data not shown). Copy number of recombinant pRS55I (PsycO-lacZ) was determined by real-time quantitative PCR, the detecting fold change of plasmid copy number was set to be I to generate a normalization factor that was subsequently used for generating the normalized fold change of promoter activity (miller units) in the crp in relative to the WT. Each experiment was done in triplicate.

EMSA results

EMSA reaction mixtures

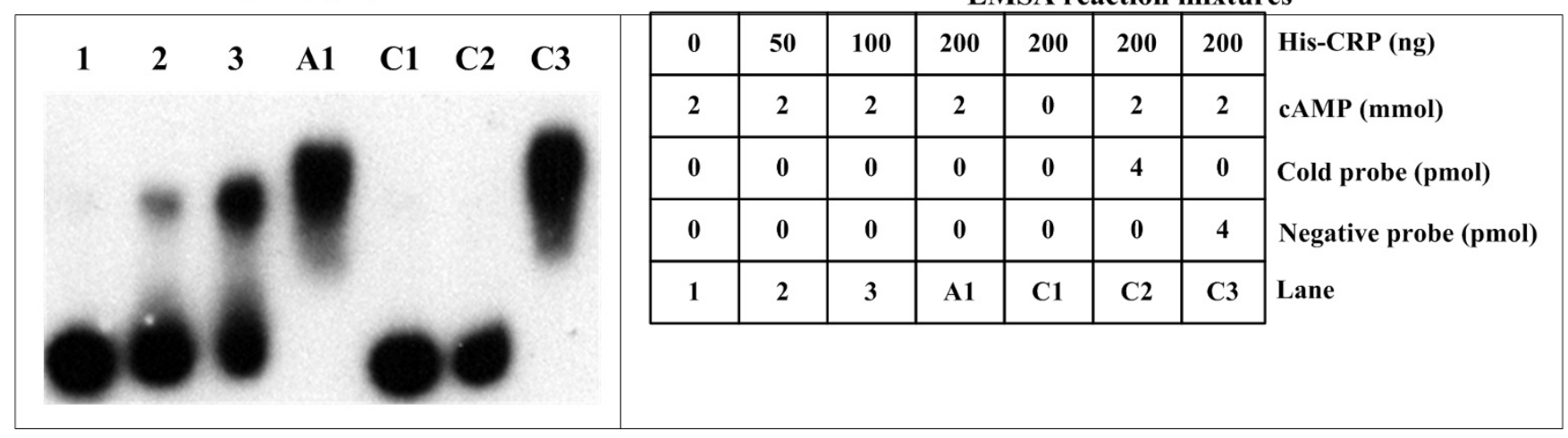

\section{a: $\operatorname{syc} O$}

PCR-generated promoter DNA probe

EMSA results

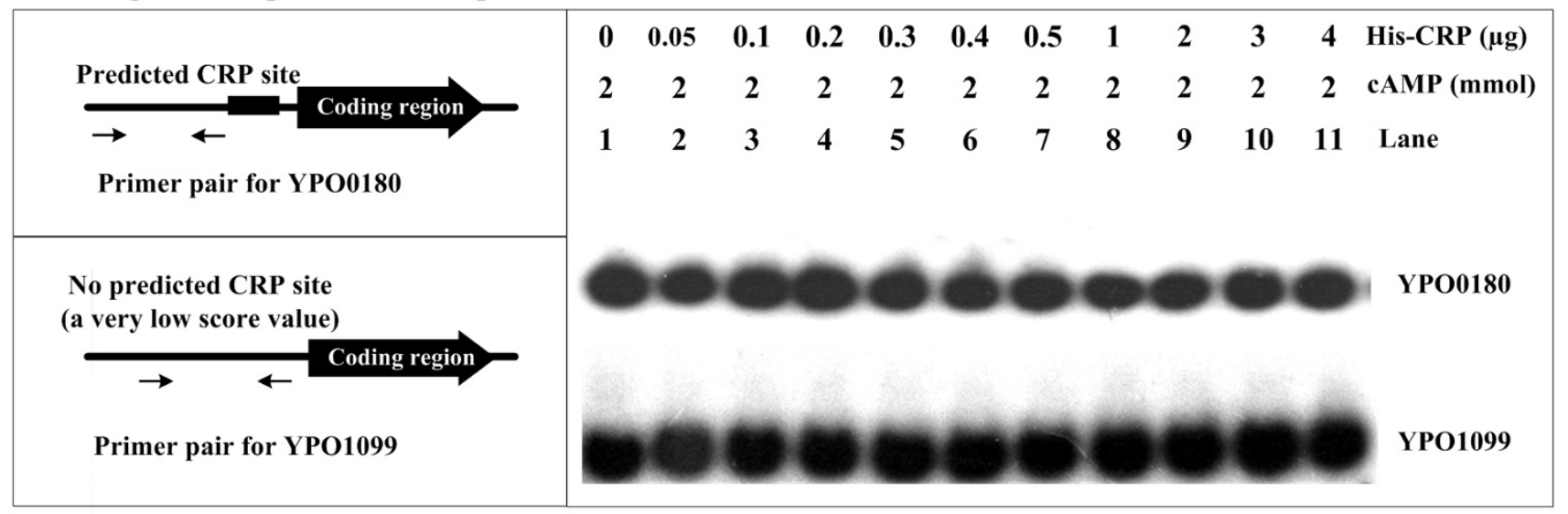

\section{b: negative controls}

Figure 3

Electrophoretic mobility shift assay. The band of DNA fragment containing the promoter region of sycO disappeared with increasing amounts of CRP protein, and a retarded DNA band with decreased mobility turned up (Fig. 3a), which presumably represented the CRP-DNA complex. But for YPO0I80 and YPOI099, the CRP-DNA complex did not appear even His-CRP was increased to $4 \mu \mathrm{g}$ for each reaction mixture (Fig. 3b). 


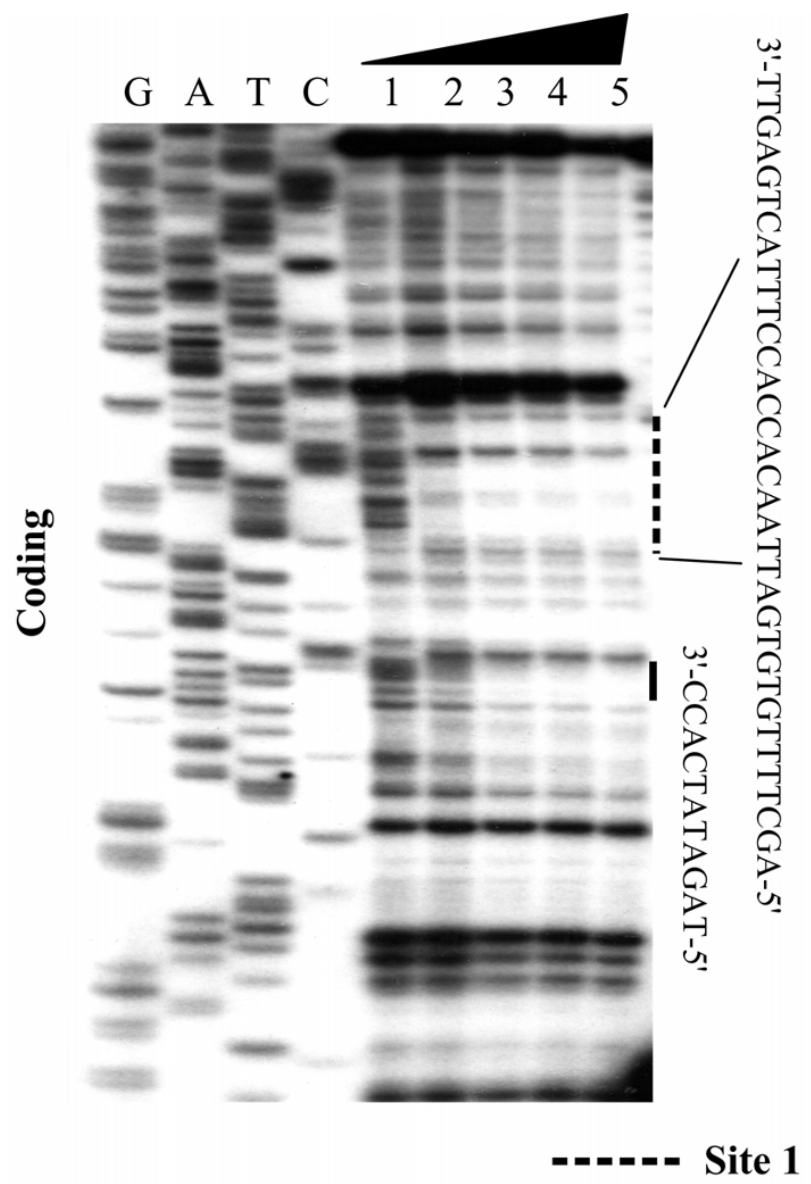

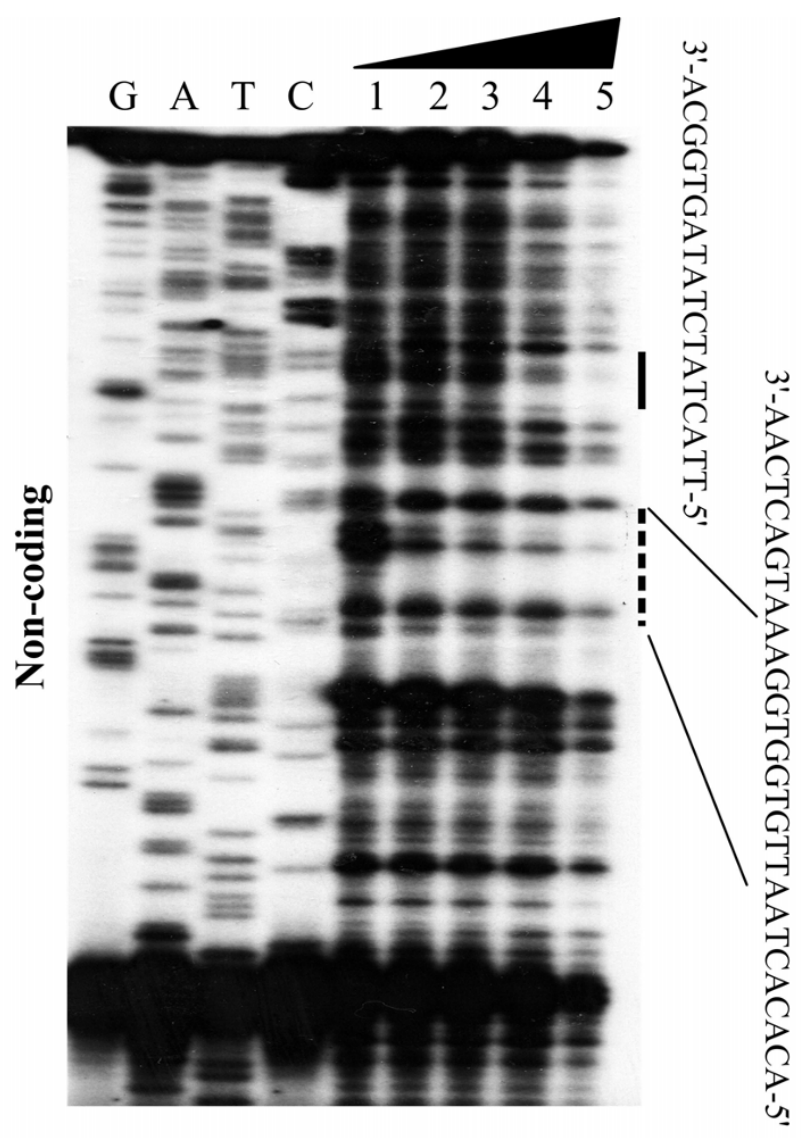

Site 2

Figure 4

DNase I footprinting assay. The labeled DNA probe was incubated with various amounts of purified His-CRP (lanes I, 2, 3, 4, and 5 contained 0, 500, 1000, 2000 and $3000 \mathrm{ng}$, respectively), and subjected to DNase I footprinting assay. Lanes G, A, T and $C$ represented the Sanger sequencing reactions. On the right-hand side was indicated the protected regions (bold line). The DNA sequences of footprints were shown from the top (3') to the bottom (5').

DNA regions (sites 1 and 2) against DNase I digestion in a dose-dependent pattern. Only site 1 contained the CRP box-like sequence.

The transcription start site of $s y c O$ was determined by primer extension assay. A single primer extension product was detected and thus a single CRP-dependent promoter was transcribed for $s y c O-y p k A-y o p J$ (Fig. 5). Compared to the WT, a much stronger primer extension product was detected in the crp. Since the yield of primer extension product would indicate the mRNA expression level of sycO in each strain, data presented here confirmed the repression of sycO-ypkA-yopJ by CRP.

The primer extension results could be also employed to map the 5' terminus of RNA transcript for sycO (i.e. the transcription start site of $s y c O-y p k A-y o p J)$ (Fig. 6). The -10 and -35 core promoter elements were predicted accordingly.

The determination of CRP-binding sites, transcription start site, and core promoter element (-10 and -35 regions) promoted us to depict the structural organization of CRP-dependent promoter, giving a map of CRP-promoter DNA interaction for sycO-ypkA-yopJ (Fig. 6).

\section{Discussion}

\section{CRP and the sycO-ypkA-yopJ operon}

CRP specifically bound to the sycO promoter-proximate region and directly repressed the expression of $s y c O-\gamma p k A$ yopJ in Y. pestis biovar Microtus strain 201. The sycO- $y p k A-$ yopJ promoter-proximate regions were extremely conserved in $Y$. pestis (including all the four biovars Antiqua [21], Mediaevalis [22], Orientalis [20] and Microtus [19]), 


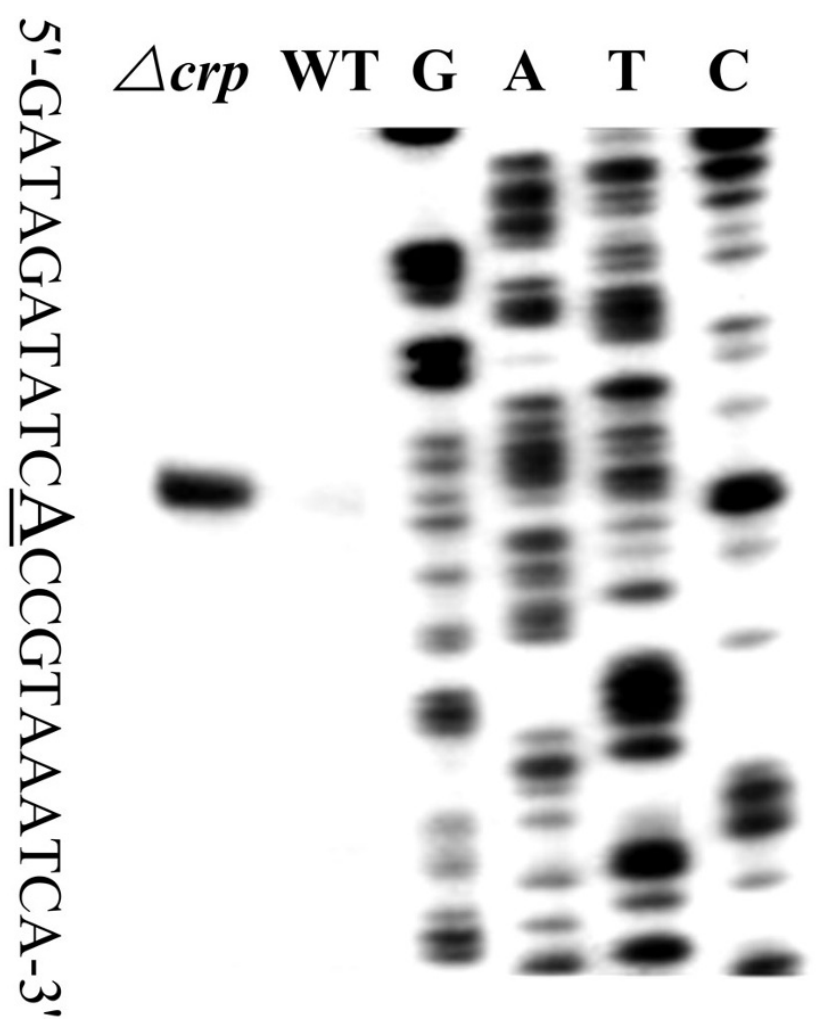

Figure 5

Primer extension analysis. Electrophoresis of the primer extension products was performed with a $6 \%$ polyacrylamide/8M urea gel. Lanes $\mathrm{C}, \mathrm{T}, \mathrm{A}$ and $\mathrm{G}$ represented the Sanger sequencing reactions. The transcriptional start sites were underlined.

Y. pseudotuberculosis [23] and Y. enterocolitica [24]. Therefore, data presented in $Y$. pestis biovar Microtus can be generally applied to the above three pathogenic yersiniae.

A single CRP-dependent promoter transcribed for the sycO-ypkA-yopJ operon, but two CRP-binding sites (site 1 and site 2) were detected within its promoter region. A CRP box-like sequence (TAGATATCACC) was found in site 1 rather than in site 2 . It was speculated that site 2 was a non-specific or non-functional CRP-binding site. Further reporter fusion experiments and/or in vitro transcription assays, using the sycO promoter-proximate regions with different mutations/deletions within sites 1 and 2, should be done to elucidate the roles of site 1 and site 2 in CRP-mediated regulation of $s y c O-y p k A-y o p J$.

\section{CRP and T3SS}

The crp mutation caused a reduced secretion of YOP proteins in both $Y$. enterocolitica [5] and Y. pestis [9] grown under calcium-depleted conditions. This indicated that CRP is a positive regulator for the YOP secretion by Y. pes- tis. It is well known that the YOP secretion phenotype is only observable under calcium depleted conditions. Herein, the direct and negative regulation of $s y c O-y p k A$ yopJ by CRP was observed at transcriptional level under calcium-rich conditions. How CRP controls T3SS is essentially unclear yet. It needs to investigate the mRNA/protein pools of T3SS that are regulated by CRP under calcium depleted or rich conditions and upon cell contact, and to answer whether CRP has a regulatory action on T3SS in general or on SycO, YpkA and YopJ specifically.

\section{CRP and virulence}

The $c r p$ deletion attenuated $Y$. pestis much more greatly by subcutaneous route of infection in relative to an intravenous inoculation, and a reduced in vivo growth phenotype of the crp mutant was observed [4]. CRP seemed more important for the infection at the subcutaneous site and in the lymph other than the later systemic infection, while the reduced in vivo growth of the crp mutant should contribute to its attenuation by intravenous infection. The crp disruption led to a great defect of pla expression [4]. Since Pla specifically promoted $Y$. pestis dissemination from peripheral infection routes, the defect of pla expression in the crp mutant will contribute to the huge loss of virulence of this mutant strain after subcutaneous infection.

Expression of Pla, Pst, F1 antigen and T3SS are dependent on CRP, and this regulator appears to control a wide set of virulence-related factors in Y. pestis [4]. All the above CRPregulated genes are harbored in plasmids that are required through horizontal gene transfer. Either the CRP protein itself or the mechanism of CRP-promoter DNA association is extremely conserved between E. coli and Y. pestis. Therefore, the above laterally acquired genes have evolved to integrate themselves into the 'ancestral' CRP regulatory cascade. It has been shown recently that the histone-like protein H-NS mediates the silencing of laterally acquired genes with low $\mathrm{G}+\mathrm{C}$ contents scattered on the bacterial genome (these H-NS-dependent genes often contribute to virulence or host adaptation in corresponding pathogens) $[25,26]$. Herein, regulation (either activation or repression) of foreign genes in plasmids was mediated by the ancient regulator CRP in the host, Y. pestis.

\section{Conclusion}

Three T3SS genes, sycO, ypkA and yopJ, constitute a single operon in $Y$. pestis. The CRP regulator binds to the upstream DNA region of $s y c O$, and represses the expression of the sycO-ypkA-yopJ operon. The sycO promoterproximate regions are extremely conserved in $Y$. pestis, $Y$. pseudotuberculosis and Y. enterocolitica, indicating that the CRP-dependent expression of sycO-ypkA-yopJ can be generally applied to the above three pathogenic yersiniae. 


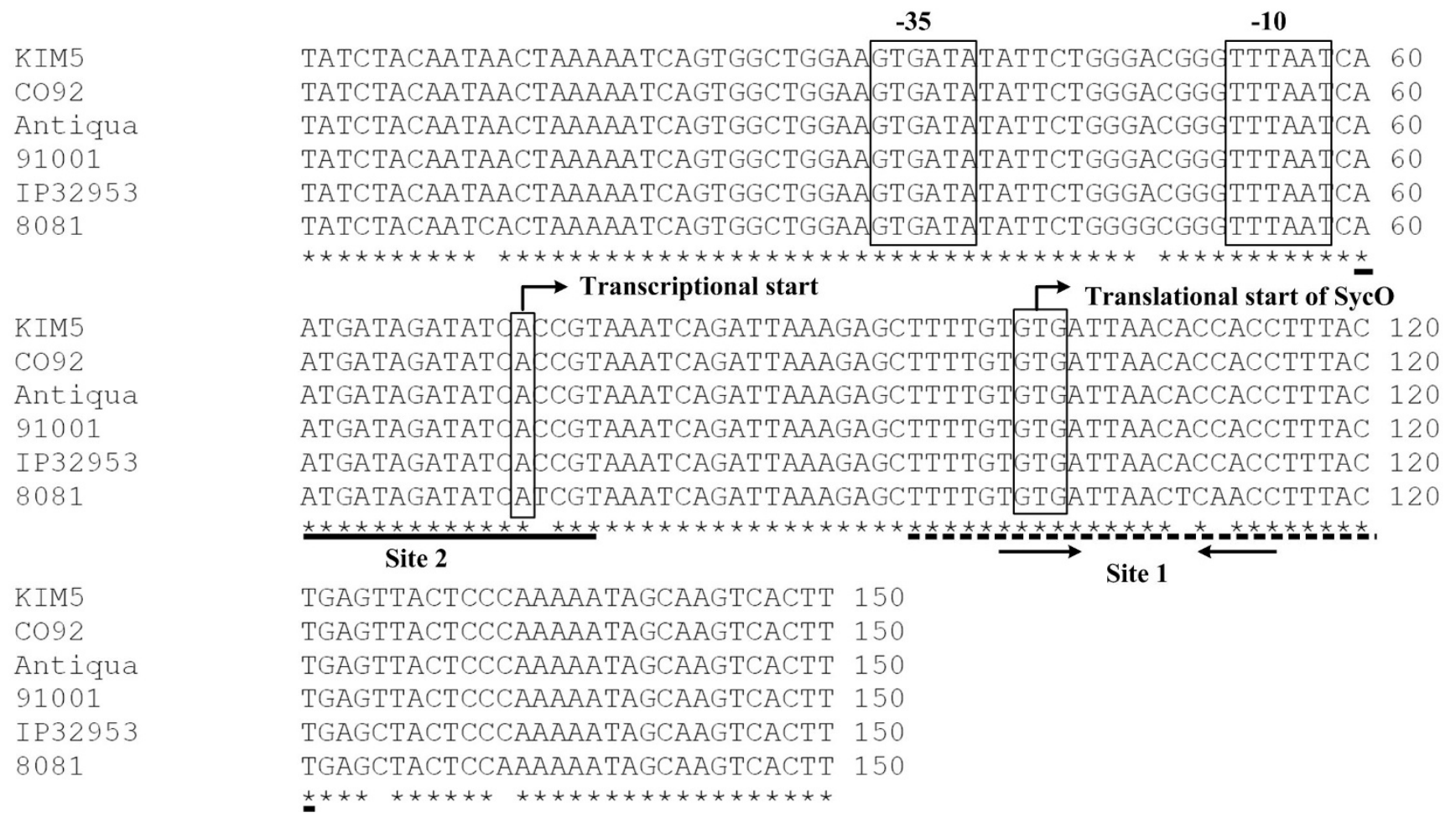

Figure 6

Structural organization of the sycO-ypkA-yopJ promoter region. The sycO-ypkA-yopJ promoter-proximate sequences ( 100 bp upstream to 50 bp downstream the start codon of sycO) from Y. pestis Antiqua (biovar Antiqua), KIM5 (Mediaevalis), CO92 (Orientalis) and 9100I (Microtus), as well as those from Y. pseudotuberculosis IP32953 and Y. enterocolitica 808I, were aligned and conserved nucleotide sites were labeled with asterisks. The CRP binding sites were underlined, and the invert repeats in the CPR box was showed with two invert arrows. Showed also were transcriptional/transcriptional start sites and promoter -10 and/or -35 elements.

\section{Authors' contributions}

$\mathrm{DZ}$ and RY conceived the study and designed the experiments. LJZ and LY performed all the experiments. LZ, YL and HG contributed to RT-PCR, primer extension assay and DNA binding assays. ZG participated in protein expression and purification. DZ, LFZ, CQ and DZ assisted in computational analysis and figure construction. The manuscript was written by LJZ and DZ, and revised by RY. All the authors read and approved the final manuscript.

\section{Acknowledgements}

Financial support for this work came from the National Natural Science Foundation of China for Distinguished Young Scholars (30525025), the National Natural Science Foundation of China (3077I I79), and the National Key Program for Infectious Disease of China (2009ZX $10004-103$ and 2008ZX10004-009).

\section{References}

I. Ramamurthi KS, Schneewind O: Type iii protein secretion in yersinia species. Annu Rev Cell Dev Biol 2002, I 8: 107-I33.

2. Trosky JE, Liverman AD, Orth K: Yersinia outer proteins: Yops. Cell Microbiol 2008, 10(3):557-565.

3. Zheng D, Constantinidou C, Hobman JL, Minchin SD: Identification of the CRP regulon using in vitro and in vivo transcriptional profiling. Nucleic Acids Res 2004, 32(19):5874-5893.
4. Zhan L, Han Y, Yang L, Geng J, Li Y, Gao H, Guo Z, Fan W, Li G, Zhang $L$, et al.: The cyclic AMP receptor protein, CRP, is required for both virulence and expression of the minimal CRP regulon in Yersinia pestis biovar microtus. Infect Immun 2008, 76 (I I):5028-5037.

5. Petersen S, Young GM: Essential role for cyclic AMP and its receptor protein in Yersinia enterocolitica virulence. Infect Immun 2002, 70(7):3665-3672.

6. Oh MH, Lee SM, Lee DH, Choi SH: Regulation of the Vibrio vulnificus hupA gene by temperature alteration and cyclic AMP receptor protein and evaluation of its role in virulence. Infect Immun 2009, 77(3): I 208-1215.

7. Skorupski K, Taylor RK: Cyclic AMP and its receptor protein negatively regulate the coordinate expression of cholera toxin and toxin-coregulated pilus in Vibrio cholerae. Proc Natl Acad Sci USA 1997, 94(I):265-270.

8. Rickman Lisa, Scott Colin, Debbie Hunt M, Hutchinson Thomas, Menendez M Carmen, Whalan Rachael, Hinds Jason, Colston M Joseph, Green J, Buxton RS: A member of the cAMP receptor protein family of transcription regulators in Mycobacterium tuberculosis is required for virulence in mice and controls transcription of the rpfA gene coding for a resuscitation promoting factor. Molecular Microbiology 2005, 56(5): I 274-I 286.

9. Kim TJ, Chauhan S, Motin VL, Goh EB, Igo MM, Young GM: Direct transcriptional control of the plasminogen activator gene of Yersinia pestis by the cyclic AMP receptor protein. J Bacteriol 2007, 189(24):8890-8900.

10. Sebbane F, Jarrett CO, Gardner D, Long D, Hinnebusch BJ: Role of the Yersinia pestis plasminogen activator in the incidence of distinct septicemic and bubonic forms of flea-borne plague. 
Proceedings of the National Academy of Sciences of the United States of America 2006, 103( I4):5526-5530.

I I. Lathem WW, Price PA, Miller VL, Goldman WE: A plasminogenactivating protease specifically controls the development of primary pneumonic plague. Science 2007, 3 I 5(58 I I):509-5 I 3.

I2. Park H, Teja K, O'Shea JJ, Siegel RM: The Yersinia effector protein YpkA induces apoptosis independently of actin depolymerization. J Immunol 2007, I 78( I 0):6426-6434.

13. Mukherjee S, Keitany G, Li Y, Wang Y, Ball HL, Goldsmith EJ, Orth K: Yersinia YopJ acetylates and inhibits kinase activation by blocking phosphorylation. Science 2006, 3 I 2(5777): |2 | |-|2 |4.

14. Viboud GI, Bliska JB: YERSINIA OUTER PROTEINS: Role in Modulation of Host Cell Signaling Responses and Pathogenesis. Annu Rev Microbiol 2005, 59:69-89.

15. Dittmann S, Schmid A, Richter S, Trulzsch K, Heesemann J, Wilharm G: The Yersinia enterocolitica type three secretion chaperone SycO is integrated into the Yop regulatory network and binds to the Yop secretion protein YscMI. BMC Microbiol 2007, 7:67.

16. Zhou D, Tong Z, Song Y, Han Y, Pei D, Pang X, Zhai J, Li M, Cui B, Qi Z, et al.: Genetics of metabolic variations between Yersinia pestis biovars and the proposal of a new biovar, microtus. J Bacteriol 2004, I 86( I 5):5 | 47-5 I 52.

17. Datsenko KA, Wanner BL: One-step inactivation of chromosomal genes in Escherichia coli K-I 2 using PCR products. Proc Natl Acad Sci USA 2000, 97( I 2):6640-6645.

18. Straley SC, Bowmer WS: Virulence genes regulated at the transcriptional level by $\mathbf{C a 2 +}$ in Yersinia pestis include structural genes for outer membrane proteins. Infect Immun 1986, 5 I (2):445-454.

19. Song Y, Tong Z, Wang J, Wang L, Guo Z, Han Y, Zhang J, Pei D, Zhou $D$, Qin $H$, et al:: Complete genome sequence of Yersinia pestis strain 9 an isolate avirulent to humans. DNA Res I00I, I I(3): I79-197.

20. Parkhill J, Wren BW, Thomson NR, Titball RW, Holden MT, Prentice MB, Sebaihia M, James KD, Churcher C, Mungall KL, et al.: Genome sequence of Yersinia pestis, the causative agent of plague. Nature 200I, 4I 3(6855):523-527.

21. Chain PS, Hu P, Malfatti SA, Radnedge L, Larimer F, Vergez LM, Worsham $P$, Chu MC, Andersen GL: Complete genome sequence of Yersinia pestis strains Antiqua and Nepal5 I 6: evidence of gene reduction in an emerging pathogen. Journal of bacteriology 2006, I 88( I 2):4453-4463.

22. Deng W, Burland V, Plunkett G 3rd, Boutin A, Mayhew GF, Liss P, Perna NT, Rose DJ, Mau B, Zhou S, et al:: Genome sequence of Yersinia pestis KIM. J Bacteriol 2002, I 84( I 6):460 I-46I I.

23. Chain PS, Carniel E, Larimer FW, Lamerdin J, Stoutland PO, Regala WM, Georgescu AM, Vergez LM, Land ML, Motin VL, et al.: Insights into the evolution of Yersinia pestis through whole-genome comparison with Yersinia pseudotuberculosis. Proc Natl Acad Sci USA 2004, I 0 I(38): I 3826-I3831.

24. Thomson NR, Howard S, Wren BW, Holden MT, Crossman L, Challis GL, Churcher C, Mungall K, Brooks K, Chillingworth T, et al.: The complete genome sequence and comparative genome analysis of the high pathogenicity Yersinia enterocolitica strain 808 I. PLoS Genet 2006, 2(I 2):e206.

25. Lucchini S, Rowley G, Goldberg MD, Hurd D, Harrison M, Hinton JC: $\mathrm{H}-\mathrm{NS}$ mediates the silencing of laterally acquired genes in bacteria. PLoS Pathog 2006, 2(8):e8I.

26. Navarre WW, Porwollik S, Wang Y, McClelland M, Rosen H, Libby S], Fang FC: Selective silencing of foreign DNA with low GC content by the H-NS protein in Salmonella. Science 2006, 3 I 3(5784):236-238.
Publish with Bio Med Central and every scientist can read your work free of charge

"BioMed Central will be the most significant development for disseminating the results of biomedical research in our lifetime. "

Sir Paul Nurse, Cancer Research UK

Your research papers will be:

- available free of charge to the entire biomedical community

- peer reviewed and published immediately upon acceptance

- cited in PubMed and archived on PubMed Central

- yours - you keep the copyright

Submit your manuscript here:

http://www.biomedcentral.com/info/publishing_adv.asp
BioMedcentral 